\title{
1 \\ Introduction: A multidisciplinary approach to ageing
}

\author{
Hal Kendig, Peter McDonald and John Piggott
}

Increasing longevity is an historic triumph and population ageing is emerging as one of the major global issues of the 21 st century. Australia's future will be deeply affected by the ageing of the baby boom cohort, with large numbers expected to reach advanced ages during a time of economic uncertainty, pressures on health budgets, and the likely need for ongoing fiscal restraint. A new policy era is emerging, illustrated by the redesign of superannuation over the last 20 years, ongoing debate about retirement incomes policy, the establishment of a Commissioner on Age Discrimination and the 'rights' approach, and consumer-led directions in the Living Longer Living Better reforms of aged care. The government's 2015 Intergenerational Report is the latest in a series of Intergenerational Reports (IGR) that serve as barometers of the sustainability of national government spending programs and raise wider questions about public policy priorities (Commonwealth of Australia 2015). These initiatives are bringing additional evidence and critical arguments to the public debates, extending consideration of ageing well beyond health and welfare concerns to a consideration of its pervasive influences on national priorities including productivity, incomes, taxation, federal relations, and population policy. 


\section{Multidisciplinary concepts on ageing: New directions}

Before reviewing social science conceptions of ageing, it is essential to recognise the social purposes of knowledge and the deep personal meanings of ageing. In an earlier statement for the Academy of Social Sciences in Australia (ASSA), we argued that 'the quest for ageing well is arguably as old as humanity itself and it is deeply embedded in individuals' consciousness and collective ideas of social advancement' (Kendig and Browning 2011). Qualitative sociology has revealed how older people strive to maintain their identities, independence, and continuity as they grow older and face opportunities as well as constraints in their lives. Among the most enduring psychological models of successful ageing is the process of selective optimisation with compensation, in which older people are understood to 'orchestrate' their lives to adjust their aspirations and make other adaptations in line with changing orientations and declining capacity (Baltes and Baltes 1990).

A constructive approach to ageing aims to understand what is 'improvable' in later life by identifying the resources and social factors that can enable positive experiences. As this volume demonstrates, there is accumulating evidence that ageing processes, previously thought to be immutable and based on biological facts, in fact have been changing and can remain changeable in the light of social forces. As Anstey demonstrates in her chapter on cognition, the phenomenon of 'plasticity' recognises that brain function is influenced by social exposures. A powerful use of social research is to understand the structural forces that accompany decline in people as they grow older, and to inform the public case for action and advocacy on their behalf.

The complexity of ageing from a social science viewpoint is apparent in the distinctions that need to be made between individual, population, and societal dimensions of ageing. Individual ageing involves complex bio-psychosocial developments embedded in the family, community, work, and social institutions in which individuals negotiate changing social relationships as they move through the life-course. Population ageing is fundamentally about the forces behind demographic change and the consequences for changing age structures. Societal ageing 
extends beyond individual and demographic ageing to encompass the social constructions of ageing and the 'treatment' of older people in wider social, cultural, economic, and political life.

It is important to appreciate the ways in which depictions of individual and societal ageing are shaped by the viewpoints of commentators. Personal views on ageing are, of course, important but they provide a very limited basis on which to assess the variation and complexity in societal ageing. The Intergenerational Reports provide reasonably objective projections on ageing populations but their interpretations, being couched in the interests of government, require careful scrutiny (Woods and Kendig 2015). The interplay between demographic imperatives and associated fiscal implications, and the social influences on individual ageing, provide the potential for a greater span of intervention than has been traditionally appreciated.

Notable advances are underway in the multidisciplinary understanding of population ageing. Among the most important is recognition that many of the age differences assumed to be inherent in ageing are, in fact, cohort phenomena grounded in the different periods of history that people have experienced during their lifetimes. We therefore need to question the relevance of studies and depictions of ageing that are based on the Depression cohort of older people now in advanced old age. Understanding the future of ageing requires an understanding of the large post-war baby boom cohort that has had strikingly different life opportunities and now faces the profound challenges of increased longevity in later life.

Cross-sequential cohort analysis is a powerful demographic method for unravelling the confounding effects of ageing and cohort progression. An important direction here is McDonald's analyses of workforce participation, which show that relatively recent entrants to later life have in fact been working longer than their predecessors during this recent period of economic uncertainty. Collaboration between ASSA and the Bureau of Statistics has brought new understandings to longevity and emergent policy and social issues (Gibson and ASSA 2010).

Our knowledge of the economic and fiscal consequences of ageing populations is being advanced in several important ways. Understanding age and intergenerational transfers in Australia-long 
a vexed topic of debate - is improving with new work on National Transfer Accounts. These accounts now span many countries, and provide powerful new bases for understanding the public and private consequences of population ageing in Australia as contrasted with comparable populations and economies. Further, a range of economywide modelling initiatives aim to inform policy formulation on the impacts of an ageing demographic on retirement incomes and pension reform (for example, Kudrna, Tran and Woodland 2015). The interplay between pension accumulations, tax treatment, public transfers and aggregate fiscal balance is complex, because both labour supply and saving behaviour (and further human capital accumulation) are affected by policy change. While these models do not capture the policy detail of micro-simulation models, they allow for the fundamental movements of relative prices and behavioural change that accompany large-scale economic policy reforms.

In sociological thinking on ageing, the life-span framework provides a powerful way to understand social processes behind age differences and ageing experiences. From a developmental perspective, the most deeply seated psychosocial orientations, values, and attitudes are largely inculcated from early childhood and these understandings are fundamental in shaping subsequent life actions and experiences. Applications of the Cumulative Advantage/Disadvantage (CAD) theory (Dannefer 2003; Dannefer and Phillipson 2010) examine the consequences of divergent life pathways as people move through social structures during their lives. The life-span approach thus enables us to better understand variation in social inequalities and other outcomes through to later life. The life-span approach also enables us to consider how investments earlier in life can yield longerterm benefits as younger people grow older and become the next generations of middle-aged and older people in the future.

A relatively new approach in life-span research builds on life history concepts and methods in order to examine the effects of earlier life experiences in later age (Kendig and Nazroo 2016). Retrospective data collection techniques are improving but consideration needs to be given to the process of selective survival, which sees many disadvantaged people dying or dropping out of studies before reaching later life. Our Australian life-course research is showing that socioeconomic circumstances, health, and education in childhood have persistent consequences for subsequent life trajectories and 
for wellbeing among the baby boom cohort on entry to later life (Kendig et al. 2015). This ongoing comparative study with England is also providing insights into the ways in which the differing postwar development experiences and policies of the two countries are influencing their ageing populations. ${ }^{1}$

The mainstay of Australian psychosocial research on ageing, as per Part 3 of this volume, is longitudinal surveys of people from midlife through advanced old age. Over the past 15 years these studies have yielded new knowledge and been used in various research programs with a variety of special foci, for example, on particular cities, women, health, income and work. But what is really needed as a national priority is a comprehensive Australian survey focused on older cohorts that is multidisciplinary, nationally representative, and can be linked to administrative data sets. The gold standard for such surveys is represented by the US Health and Retirement Survey (HRS), the English Longitudinal Survey of the Aged (ELSA), and the Survey of Health, Ageing and Retirement in Europe (SHARE). These studies cover multiple dimensions including family circumstances, health status - both self-assessed and through biomarkers - work and retirement, financial conditions, and cognitive ability, and service use. Questions, while not identical, are harmonised across countries, and this family of surveys now covers two-thirds of the world's population.

Our ageing population means that it is increasingly urgent that Australian researchers be given access to survey information of this kind. Using a format that harmonises with existing international studies, while taking careful account of the Australian context, would immeasurably strengthen the value of the data. Australia would be included in international studies using this 'state of the art' method, and cross-national studies by Australian researchers would be facilitated. The data bank could be made available widely on a public access basis with appropriate privacy protections.

\footnotetext{
1 They include the Australian Longitudinal Survey on Ageing (ALSA) (with innovative couples research) (Luszcz et al. 2014); the Personality and Total Health (PATH) cross-sequential study through the life-span (Anstey et al. 2011); the Melbourne Longitudinal Surveys of Ageing (MELSHA) (now completed so experiences through to the end of life can be examined) (Browning and Kendig 2010). The large-scale 45 and Up study (45 and Up Study Collaborators 2008) and the Australian Longitudinal Survey of Women's Health (Byles et al. 2015) have large samples and they are also notable for data linkages to administrative records. The DYNOPTA study (Anstey et al. 2010) has attempted to coordinate these various surveys.
} 
Studies of ageing also need to take account of younger people and generational differences and relationships. Indeed, as Jean Martin demonstrated in her classic study, The Migrant Presence (1978), some of the best insights into a subgroup of a society and the social challenges they face can be revealed by observing mainstream views about them ${ }^{2}$ (see also Shaver et al. 2015). As emphasised in the Symposium Opening Address by the Age Discrimination Commissioner Susan Ryan, attitudes and related practices towards older people in the community and in workplaces are powerful influences on older people's self-respect and their opportunities for economic independence. A CEPAR-supported national Attitudes to Ageing study (Kendig et al. 2015) has examined the views of different age groups on intergenerational equity. It is also examining perceptions of the respect accorded to older people in everyday life and their 'social treatment' in other spheres of life including the workplace and health care. A follow-up survey now in the field will examine ways in which attitudes have changed over the 2010-17 period of significant policy and socioeconomic change.

The broader, social determinants' literature reminds us that health and wellbeing are influenced not only by our absolute access to economic and social resources but also by our 'social positions' relative to those of others in work, local communities, and other spheres of life. Wilkinson and Pickett (2011) make a UK-based case that social inequalities not only disadvantage individuals but also erode societal capacities for achieving health, wellbeing, and productivity. However, inclusion of ageing in these broader, social and political debates on public health, in Australia as well as overseas, has been surprisingly limited (Schofield 2015). For example, while the English Marmott Review took a life-span approach in its landmark Fair Society Healthy Lives report, the emphasis was on opportunities in early and mid-life; the recommendations for later life were largely restricted to concerns for comfort or care (Kendig and Phillipson 2014).

2 Martin's impeccable scholarship, as an empirical anthropologist informed by social theory, was brought to full public engagement through her 1978 report commissioned by the demographer Mick Borrie when he led the National Population Inquiry. Shaver and colleagues' recent intellectual biography The Martin Presence: Jean Martin and the Making of the Social Sciences in Australia, has documented how she established a continuing 'social science for public knowledge' that has made deep contributions to understanding and building multiculturalism and public responses to social inequalities. 


\section{International perspectives}

Understanding global priorities on ageing and Australia's comparative position in the region and internationally provides an important context for addressing ageing in Australia. Australia is a significant contributor to international work on ageing and gerontology (Kendig, Lucas and Anstey 2013) and in turn benefits from knowledge and collaboration in regional and global initiatives. We are increasingly connected with other countries through trade and political engagement with ageing emerging as an area of national opportunity, for example, in the development of pensions and health and aged care in China. At the same time, Australia faces increasing global competition for skilled workers and investment.

An international perspective is also helpful in benchmarking how well Australia is faring in addressing ageing issues. Appendix 1 outlines the notable societal variations in the dimensions of population ageing and ageing well outcomes for Australia in comparison to other countries reviewed in Part 2 of this volume as well as New Zealand, the UK, and the US. As reviewed in Kendig and Browning's chapter, positive directions on ageing are being determined by the United Nations, World Health Organization, World Bank, and other international organisations.

International scholarship is moving beyond conceptual development and empirical research to challenge established thinking and is seeking to 're-image' societal directions on ageing. In their aptly titled 'Rethinking Age and Ageing', the demographers Sanderson and Scherbov (2008) observe that, with increasing life expectancy, public policy will need to take more account of life expectancy beyond a given age (e.g. 65 years as a traditional age of retirement) relative to expectancy at birth. Several decades ago, Riley, Kahn and Foner (1994) provided a sociological analysis of what even today are still 'lost opportunities' as a result of 'age and structural lag: society's failure to provide meaningful opportunities in work, family, and leisure'. Their argument is that rigid social institutions, outdated attitudes, and entrenched interests have yet to adapt to the increasing capacities and potential of older people. The emergent idea of a third age, where increasing numbers of capable people are in a new life stage - between a second age of paid work and a fourth age of dependence-raises 
important questions as to the uses of these additional years of later life. The English historian Peter Laslett (1989) observed that the relatively recent emergence of 'this third age' can be approached as 'a fresh map of life'.

In summary, this brief review has aimed to illustrate concepts and research directions in the social sciences that are contributing to policy-relevant thinking about population ageing in Australia. It has drawn principally on work in the disciplines of demography, economics, public health, psychology, and sociology as well as the field of social gerontology. It is important to note the range of contributions from across the social sciences-including anthropology, history and political science - to a broader understanding of ageing and its social and policy applications. There also is a large international literature in each of these areas as can be seen in the Handbook of Aging and the Social Sciences (George and Ferraro 2016), the Handbook of the Psychology of Aging (Schaie and Willis 2015), and the SAGE Handbook of Social Gerontology (Dannefer and Phillipson 2010). While each of the disciplines has their specialised contributions, the case advanced in this volume is that a comprehensive multidisciplinary approach has the greatest potential to address the complex, multidimensional challenges of an ageing Australia.

\section{Volume overview}

This volume aims to bring a scholarly and policy-relevant approach to critically assess the outlook for Australia of the population ageing changes that arguably are among the most significant in human history. The chapters draw on multiple social science disciplines to marshall ideas and evidence to inform constructive actions to address the public and policy challenges ahead.

Part 1 presents perspectives on ageing that underpin the social science approach taken in later chapters on specific topics. This first chapter outlines our multidisciplinary directions in advancing ageing research and policy.

Gong and Kendig, an economist and a sociologist, then examine historical developments that have shaped Australia's emerging response to ageing over the post-war era and directions for the future. 
They demonstrate how the post-war baby boom cohort has been at the centre of profound socioeconomic and policy changes that have shaped their life trajectories towards later life and consequences for quality of life, social inequalities, and intergenerational equity.

In his chapter, Piggott, an economist, reviews emerging policy challenges in the areas of retirement and retirement incomes, health and aged care, infrastructure and housing, and regionalisation. He recognises that issues of intergenerational relationships, taxation and international interactions present considerable challenges and he points towards ways of addressing them.

Part 2 considers demographic change and diversity in Australia with the perspective of related international developments. McDonald assesses the demographic scenarios that underlie the four Intergenerational Reports that present evolving government views on Australia's ageing future. He shows that, with each successive report, the newer demographic projections have placed Australia in a much more favourable position in relation to population ageing than almost all other developed countries on the basis of current policy settings. The implication for Australia is that population ageing requires longterm sensible planning not hasty short-term fixes.

Can the effects of population ageing be mitigated through pronatalist policy approaches? Ogawa, Matsukura and Lee investigate comprehensive National Transfer Accounts for eight Asian countries with rapidly ageing populations to examine health and education costs of children as key influences on fertility rates and the 'quality' of children. They argue that higher wages for younger workers would lower the age at which young people become self-supporting and thus contribute to somewhat earlier childbearing.

Pakulski reviews European experiences with socioeconomic and policy issues in population ageing. These include changing health profiles, reduced dynamism in the workforce and requirements for developing health, housing, and retirement income systems that are fair and adequate but also efficient and affordable. He compares policy options for Australia and Poland in terms of the fundamental '4Ps': Population growth through immigration; Participation rates that increase the labour force; Productivity by promoting innovation and investment; and Pensions, or, more broadly, effective income-support 
programs. He suggests that similar policy approaches can be applied to mitigate or adapt to population ageing by countries with different economic and political contexts.

Part 3 moves beyond negative images of ageing, with their emphases on decline and dependency, to consider social and societal options for improving health and wellbeing. Kendig and Browning examine research and action on 'ageing well' as a constructive approach to investing in health capacities over the life-course, and maintaining and recovering health and wellbeing in later life through self-care and health promotion. In her chapter on enhancing cognitive capacities, Anstey presents ground-breaking research on how psychological and social actions over the life-span can improve cognitive capacities as resources for independence, contributions and wellbeing in an increasingly complex Australia.

Windsor, Curtis and Luszcz consider social engagement as a hallmark of ageing well. Their chapter shows how social networks provide resources for navigating transitions through retirement, managing the challenges of advanced old age, and making contributions to families and communities. They present evidence-based approaches to combating social isolation and other interventions for promoting social engagement in later life.

Burns and Browning critically assess the emerging science of wellbeing for individuals and its importance for population-level policy. They recognise the importance of including social as well as economic indicators of a nation's 'wealth'. They reflect on the way forward in terms of incorporating wellbeing outcomes in Australian national policy, and the measurement and data collection issues that need to be addressed.

The final part of this volume concentrates on policy challenges and responses by governments and by families and individuals, with an emphasis on retirement income strategies, health and financing agedcare services.

Bateman analyses Australia's relatively new and highly regarded retirement income strategies that include the age pension, the superannuation guarantee and voluntary superannuation and other savings. She concludes that the Australian retirement income system relies on engaged, highly skilled, knowledgeable individuals 
to make good financial decisions throughout their life. However, problems remain with poor financial literacy and poor understanding of retirement income products as well as substandard financial advice. She asserts that while the accumulation phase of retirement income saving has a high policy focus, the same cannot be said for the deaccumulation phase that leaves Australian retirees vulnerable to investment risk, inflation risk and longevity risk.

Hall and van Gool focus on the impact of an ageing population on the costs to health care. Contrary to much of the conventional assumptions, their chapter concludes that ageing per se is not necessarily a threat to the sustainability of the Australian health-care system. They make the case that redesigning incentives and services and making better use of the options provided by modern technology are essential to meet the challenges of chronic and continuing illnesses.

Ong considers options for financing aged-care services in the context of a projected doubling of costs to government by 2050. Financial pressure over the life-span is increasing for individuals as government is requiring more user contributions to education (usually earlier in life) as well as to care costs in later life. She proposes a housing assetbased system of paying for care given that people now approaching retirement are likely to have more savings, high home ownership rates and high home values. The trend towards more private and public co-funding of services does, however, raise concerns about inequalities experienced by the increasing numbers of people who have not attained home ownership as they grow older.

Podger concludes the volume with his interpretation of the chapters and notes that the historic triumph of ageing nonetheless presents 'big' policy challenges. He reviews the substantial scope for individuals' own actions as well as comprehensive policy development to improve prospects for an ageing Australia:

- Social and economic participation of older people could be enhanced through reconsidering the concept of retirement in the light of increasing longevity and capacities in later life.

- Health and wellbeing could be enhanced by improved retirement income systems, better public health programs and health services inclusive of ageing people, and improved community engagement. 
Overall, while Australia fares well with population ageing and the wellbeing of older people, international comparisons show that it has a way to go before reaching the world's best standards for ageing societies (Appendix 1).

\section{Concluding remark}

New social science thinking and evidence point the way towards social, economic, and political changes that can improve individual and population ageing but many areas remain unexplored. More critical thinking and research investment is required in priority areas for personal wellbeing and policy action:

- healthy and productive ageing

- fertility and migration

- labour force participation and retirement

- longevity risk and risk management

- changing family structures and intergenerational relations

- the organisation of care and support.

We need to be aware of the variable ways in which population ageing impacts on successive cohorts of men and women, advantaged and disadvantaged social groups, and the overall wellbeing of Australian society. Attitudinal and political factors set a changing social context that can facilitate or impede constructive responses. The implications of the staged timing of different societal ageing impacts and changes in the life-course also need to be explored further.

In conclusion, this volume is a testament to the range of research and thinking being conducted on population ageing. At the same time, it is a call for new research, policy and public affairs initiatives addressing what is one of the most important social phenomena of the 21 st century. 


\section{References}

45 and Up Study Collaborators (2008). Cohort profile: The 45 and Up Study. International Journal of Epidemiology, 37(5): 941-947. doi:10.1093/ije/dym184.

Anstey Kaarin, Byles Julie, Luszcz Mary, Mitchell Paul, Steel David, Booth Heather, Browning Colette, Butterworth Peter, Cumming Robert, Healy Judith, Windsor Tim, Ross Lesley, Bartsch Lauren, Burns Richard, Kiely Kim, Birrell Carole, Broe Tony, Shaw Jonathan, and Kendig Hal (2010). Cohort profile: The Dynamic Analyses to Optimize Ageing (DYNOPTA) project. International Journal of Epidemiology, 39(1): 44-51.

Anstey Kaarin, Christensen Helen, Butterworth Peter, Easteal Simon, Mackinnon Andrew, Jacomb Trish, Maxwell Karen, Rodgers Bryan, Windsor Tim, Cherbuin Nicolas and Jorm Anthony (2011). Cohort Profile: The PATH through life project. International Journal of Epidemiology, 41(4): 1-10. doi:10.1093/ije/dyr025.

Baltes Paul and Baltes Margret (1990). Psychological perspectives on successful aging: The model of selective optimization with compensation. In PB Baltes and MM Baltes (Eds), Successful Aging: Perspectives from the Behavioral Sciences. Cambridge: Cambridge University Press, pp. 1-34.

Browning Colette and Kendig Hal (2010). Cohort profile: The Melbourne Longitudinal Studies on Healthy Ageing Program. International Journal of Epidemiology, 39(5): el-e7.

Byles Julie, Hockey Richard, McLaughlin Dierdre, Dobson Annette, Brown Wendy, Loxton Deborah, Mishra Gita (2015). Chronic conditions, physical function and health care use: Findings from the Australian Longitudinal Study on Women's Health, Report prepared for the Australian Government Department of Health, June 2015. www.alswh.org.au.

Commonwealth of Australia (2015). 2015 Intergenerational Report: Australia in 2055. Canberra: Department of Treasury. www. treasury.gov.au/PublicationsAndMedia/Publications/2015/2015Intergenerational-Report. 
Dannefer Dale (2003). Cumulative advantage/disadvantage and the life course: Cross-fertilizing age and social science theory. Journals of Gerontology Series B: Psychological Sciences and Social Sciences, 58(6): S327-S337.

Dannefer Dale and Phillipson Chris (Eds) (2010). The SAGE Handbook of Social Gerontology. London: Sage Publications, pp. 459-471.

George Linda and Ferraro Kenneth (Eds) (2016). Handbook of Aging and the Social Sciences (8th edition). San Diego, USA: Elsevier Science Publishing Co. Inc.

Gibson, Diane and The Academy of the Social Sciences in Australia (ASSA). (2010). Beyond life expectancy, Occasional Paper 2010: C5\#5, Canberra: The Academy of the Social Sciences in Australia. www.assa.edu.au/publications/occasional/111.

Kendig Hal and Browning Colette (2011). Directions for ageing well in a healthy Australia. Dialogue, Canberra: Academy of the Social Sciences in Australia, 31(2): 22-30.

Kendig Hal and Nazroo James (Eds) (2016). Life Course Influences on Inequalities in Later Life: Comparative Perspectives. Special Issue, Journal of Population Ageing, 9(1): 1-7.

Kendig Hal and Phillipson Chris (2014). Building Age-Friendly Communities: New Approaches to Challenging Health and Social Inequalities. In N Denison and L Newby (Eds) 'If you could do one thing...' Nine local actions to reduce health inequalities. British Academy Policy Centre, pp. 102-111. www.britac.ac.uk/policy/ Health_Inequalities.cfm.

Kendig Hal, Loh Vanessa, O'Loughlin Kate, Byles Julie and Nazroo James (2016). Pathways to Well-Being in Later Life: Socioeconomic and Health Determinants across the Life Course of Australian Baby Boomers. Journal of Population Ageing, 9(1): 49-67. doi: 10.1007/ s12062-015-9132-0.

Kendig Hal, Lucas Nina and Anstey Kaarin (2013). Thirty years of the United Nations and Global ageing: An Australian perspective. Australasian Journal on Ageing, 32(s2): 28-34. doi: 10.1111/ ajag.12101. 
Kendig Hal, O'Loughlin Kate, Hussain Rafat, Heese Karla and Cannon Lisa (2015). Attitudes to Intergenerational Equity: Baseline Findings from the Attitudes to Ageing in Australia (AAA) Study. CEPAR Working Paper, 2015/33. Sydney: ARC Centre of Excellence in Population Ageing Research.

Kim Sarang, Sargent-Cox Kerry, French Davina, Kendig Hal and Anstey Kaarin (2012). Cross-national insights into the relationship between wealth and wellbeing: A comparison between Australia, the United States of America and South Korea. Ageing \& Society, 32: 41-59. doi: 10.1017/S0144686x11000080.

Kudrna George, Tran Chang and Woodland Alan (2015). The dynamic fiscal effects of demographic shift: The case of Australia. Economic Modelling, 50(C): 105-122. doi:10.1016/j.econmod.2015.05.010.

Laslett Peter (1989). A Fresh Map of Life: The emergence of the third age. London: Weidenfeld and Nicolson.

Luszcz Mary, Giles Lynne, Anstey Kaarin, Browne-Yung Kathryn, Walker Ruth and Windsor Tim (2014). Cohort Profile: The Australian Longitudinal Study of Ageing (ALSA). International Journal of Epidemiology 1-10. doi: 10.1093/ije/dyul96.

Martin, Jean (1978). The Migrant Presence, Australian Responses 1947-1977, Research Report for the National Population Inquiry. Sydney: George Allen \& Unwin.

Productivity Commission (2013). An Ageing Australia: Preparing for the Future. Research Report, Canberra: Productivity Commission.

Riley Matilda, Kahn Robert and Foner Anne (1994). Age and Structural Lag: Society's failure to provide meaningful opportunities in work, family, and leisure. New York: Wiley.

Sanderson Warren and Scherbov Sergei (2008). Rethinking Age and Ageing, Population Bulletin, 63(4): 1-16.

Schaie Warner and Willis Sherry (Eds) (2015). Handbook of the Psychology of Aging (8th edition). San Diego, United States: Elsevier Science Publishing Co. Inc.

Schofield Tom (2015). A Sociological Approach to Health Determinants. Cambridge: Cambridge University Press. 
POPULATION AGEING AND AUSTRALIA'S FUTURE

Shaver Sheila, Beilharz Peter and Hogan Trevor (2015). The Martin Presence: Jean Martin and the Making of Social Sciences in Australia. Sydney: UNSW Press.

Wilkinson Richard and Pickett Kate (2011). The Spirit Level: Why Greater Equality Makes Societies Stronger. New York: Bloomsbury Press.

Woods Mike and Kendig Hal (2015). The Intergenerational Report 2015: A limited and political view of our future. Australasian Journal on Ageing, 34(4): 217-219. doi: 10.1111/ajag.12293. 
This text is taken from Population Ageing and Australia's Future, edited by Hal Kendig, Peter McDonald and John Piggott, published 2016 by ANU Press, The Australian National University, Canberra, Australia. 